\title{
TSC2 Deletions and Duplications: A Descriptive Study in Iranian Patients Affected with Tuberous Sclerosis
}

\author{
Hossein Ramandi ${ }^{1}$, Sayyed Mohammad Hossein Ghaderian ${ }^{1}$, Parviz Toosi ${ }^{1}$, \\ Seyyed Hassan Tonekaboni' ${ }^{1}$, Ahmad Ebrahimi' ${ }^{2}$, Nasim Hatamnejadian ${ }^{3}$ \\ ${ }^{1}$ Medical Genetics Department, Shahid Beheshti University of Medical Sciences, Tehran, Iran \\ ${ }^{2}$ Pediatric Neurology Research Center, Shahid Beheshti University of Medical Sciences (SBMU), Tehran, Iran \\ ${ }^{3}$ Cellular and Molecular Research Center, Research Institute for Endocrine Sciences, Shahid Beheshti University \\ of Medical Sciences, Tehran, Iran \\ Email: sghaderian@yahoo.co.uk
}

Received 8 May 2014; revised 7 June 2014; accepted 6 July 2014

Copyright (C 2014 by authors and Scientific Research Publishing Inc.

This work is licensed under the Creative Commons Attribution International License (CC BY). http://creativecommons.org/licenses/by/4.0/

(c) (i) Open Access

\section{Abstract}

Tuberous sclerosis complex (TSC) is an autosomal dominant disorder characterized by formation of benign tumors called hamartomas. Although the TSC is diagnosed based on clinical findings but approximately $85 \%$ of individuals who meet diagnostic criteria for TSC a mutation can be identified in TSC2 $(69 \%)$ and TSC1 (31\%). A review of mutation type in TSC1 \& TSC2 genes reveals that deletion/duplication assay could be a good screening strategy as a first step in TSC molecular diagnosis. All 41 exons and 5' untranslated region of TSC2 gene in addition to adjacent PKD1 gene were screened for deletion/duplication in 81 patients DNA samples using multiplex ligation dependent probe amplification (MLPA) method. Deletion/duplication was found in 29 (35.8\%) patients, including deletions in $26(32.0 \%)$ patients and duplication in $3(3.8 \%)$. Genotype/phenotype analysis, showed five patients with renal function impairment who have large deletions including PKD gene area. Approximately $65 \%$ of cases were sporadic, while the remaining have familial positive history. Deletions/duplications of TSC2 gene were seen in $35.8 \%$ of patients with TSC. So it could be concluded that MLPA is a useful testing strategy for molecular screening in sporadic forms of TSC patients. MLPA increased the detection of TSC mutations. MLPA is less expensive, quicker and more precise than direct sequencing and southern blot in the characterization of TSC deletions. This technique is recommended as a standard part of TSC clinical molecular diagnosis.

\section{Keywords}

Tuberose Sclerosis Complex, TSC2, MLPA, Iran

\footnotetext{
${ }^{*}$ Corresponding author.
}

How to cite this paper: Ramandi, H., Ghaderian, S.M.H., Toosi, P., Tonekaboni, S.H., Ebrahimi, A. and Hatamnejadian, N. (2014) TSC2 Deletions and Duplications: A Descriptive Study in Iranian Patients Affected with Tuberous Sclerosis. American Journal of Molecular Biology, 4, 163-167. http://dx.doi.org/10.4236/ajmb.2014.43018 


\section{Introduction}

Tuberous sclerosis complex (TSC) is a multisystem disorder associated with hamartomas formation in the brain, skin, heart, and other viscera [1] [2], with Epilepsy as the most common presenting symptom [3]. The incidence of TSC is estimated to be 1 in 6000 to 1 in 10,000 live birth [4]. The autosomal dominant pattern of TSC inheritance comes from a mutation in either the TSC1 or TSC2 gene [5] [6]. Both serve as tumor suppressors and inactivating mutations in either gene is associated with the formation of hamartomas [7]. Although familial TSC shows an equivalent representation of mutations in TSC1 and TSC2, sporadic cases are more associated with mutations in the TSC2 gene and have severe symptoms [1] [5] [8].

Missense mutations in TSC2 which disrupt its ability to bind to TSC1 have been identified in TSC patients [1] [9]. TSC2 located on chromosome 16p13.3.38, contains 41 exons and encodes a 200-kDa protein called tuberin [1] [4]. Mutations in TSC2 are four times more common and have more severe clinical symptoms than those of TSC1 [5] [10]. According to Human Genome Mutation Data Base (www.HGMD.org) roughly more than 45\% of TSC1 \& TSC2 mutations are deletions/duplications.

Renal problems have been observed in some sporadic patients as a relatively sever phenotype caused by a large deletion involving both TSC2 and PKD1 locus which is located 60bp downstream of TSC2 in a tail-to-tail orientation [6] [11].

Scientists are looking for a genius method to screen TSC2 and TSC1 gene mutations through populations as a fast cost benefit screening test before entire gene direct sequencing. Multiplex ligation dependent probe assay (MLPA) has been recently developed by MRC Co. as a method to identify deletion/duplication mutations as copy number variations (CNVs). This method enables accurate copy number determination of multiple (up to 40) genomic regions, by utilizing an oligonucleotide ligation assay with embedded universal primer sequences [10] [11].

In this study we applied commercially available TSC2 MLPA probe sets to enable comprehensive analysis of all exons within TSC2 for deletions and duplications in 81 Iranian TSC patients.

\section{Experimental Section}

\subsection{Patients}

All 81 TSC patients enrolled in our study were admitted to the Mofid Hospital, Shahid Beheshti University of medical sciences, Tehran, Iran. The study was approved by the local ethical committee of Mofid Hospital. Informed consent was obtained from all study participants prior to their inclusion in the study. Clinical criteria for a TSC diagnosis of Patients was determined by clinicians which has been previously published [3].

\subsection{DNA Extraction Techniques and MLPA Method}

DNA was extracted from peripheral blood samples by standard methods and qualified by Thermo fisher Nano drop, 2000 model. Multiplex ligation-dependent probe amplification was performed following the directions provided by MRC Holland, Amsterdam, The Netherlands (www.mlpa.com), using the probe set for TSC2 (SALSA MLPA kit P046-C1-1011) covering each of the 41 exons of the TSC2 gene. In addition, it contains one probe for the PKD1 gene next to TSC2 and 8 reference probes for sequences located on other chromosomes. To complete and verify our investigations we also used another probe set for TSC2 (SALSA MLPA kit P337-A20510) containing one probe for PKD1, 10 reference probes, 37 probes for exons and two for upstream regions of TSC2. In order to initial denaturation, $5 \mu \mathrm{l}$ genomic DNA $(20 \mathrm{ng} / \mu \mathrm{l})$ was incubated at $98^{\circ} \mathrm{C}$ for 5 minutes. Samples were cooled to room temperature and were mixed with $1.5 \mu \mathrm{l}$ of probes mix (containing $1.5 \mu \mathrm{mol}$ of each probe) and $1.5 \mu \mathrm{l}$ of SALSA hybridization buffer. The procedure followed by 2 min denaturation at $95^{\circ} \mathrm{C}$ and 16 hours hybridization at $60^{\circ} \mathrm{C} .32 \mu \mathrm{l}$ ligation mixture added to the hybridized probe to be ligated at $54^{\circ} \mathrm{C}$ for 15 min. After heat inactivation, $30 \mu \mathrm{l}$ of PCR buffer added to $10 \mu \mathrm{l}$ of ligation reaction heated to $60^{\circ} \mathrm{C}$. PCR amplification for 30 cycles was done for each sample after adding $10 \mu \mathrm{l}$ PCR mixture (Salsa polymerase, dNTPs, and universal primers, one of which was labeled with Xuorescein). MLPA result was considered uninterpretable when the SD of normalized signal for probes was $>0.15$; in those cases, MLPA analysis was repeated. Fragment analysis was done for all amplification products by DNA sequencer machine CAC13130ABI. Finally fragment analysis outputs were evaluated using gene marker software V. 1.85. 


\section{Results and Discussion}

Clinical and Para clinical Manifestations of 28 girls and 53 boys affected with TSC showed a range of 7 - 180 months for age of the patients. The most common manifestation were Hypo pigmented malecules (82.7\%). About $29.6 \%$ of the patients have positive familial history of TSC but only sixteen families (19.8\%) had a consanguineous marriage. In the other word about $70.4 \%$ showed a sporadic form without positive history of TSC in pedigree.

We used MLPA technique to screen 81 TSC patient DNA samples for genomic deletions and duplications of TSC2 gene and contiguous deletions of TSC2 and the adjacent PKD1. 29 cases (35.8\%) were identified with Deletions/duplications in TSC2 gene (Figure 1). Only three of the identified mutations were genomic duplications, while all others were deletions. Considering 26 deletions, 18 (69.2\%) were defined as large deletions, of which two of them extended to 5'UTR, 4 (15.4\%) were deletions of two adjacent exons, 3 (11.5\%) were deletions of just a single exon, there were also one sample (3.8\%) showing deletion only in 5'UTR. Exons 21 - 41 were defined as mutational hotspots. Five samples showed deletion in PKD1 gene, these samples had no retinal cysts. Four of these were sporadic and one of them had a familial history of TSC. Genotype-phenotype analysis showed that none of five patients with retinal problems had deletions in PKD1. 57 (70.37\%) patients had no familial history of Tuberous Sclerosis, including those cases with only one of symptoms of TSC, and 24 (29.63\%) with at least one affected family member (Table 1). All clinical aspects of studied patients have been previously announced [3].

Tuberous sclerosis complex is an autosomal dominant disorder caused by mutations in either TSC1 or TSC2 gene. Screening these mutations in different populations could help to unravel complexities of the disease and find a new and faster way of diagnosis for TSC. Studies on TSC and many other human diseases have shown that MLPA is a highly sensitive technique to identify many aspects of widespread deletions/duplications [12] [13]. We used MLPA to detect deletion/duplication mutation in TSC2 gene of 81 patients with TSC. We also checked for probable contiguous deletions of TSC2 and the adjacent PKD1. We found that 64.5\% of all patients had mutations in TSC2; these data are similar to those previously done in different populations and showed strong relation between TSC2 deletions/duplications and Tuberous Sclerosis [7] [10] [14]. The samples with no mutations in TSC2 are going to be analyzed for mutations in TSC1 gene. Those with deletions duplications in TSC2 are going to undergo target analysis for detection of the main area of mutation, in our future studies.

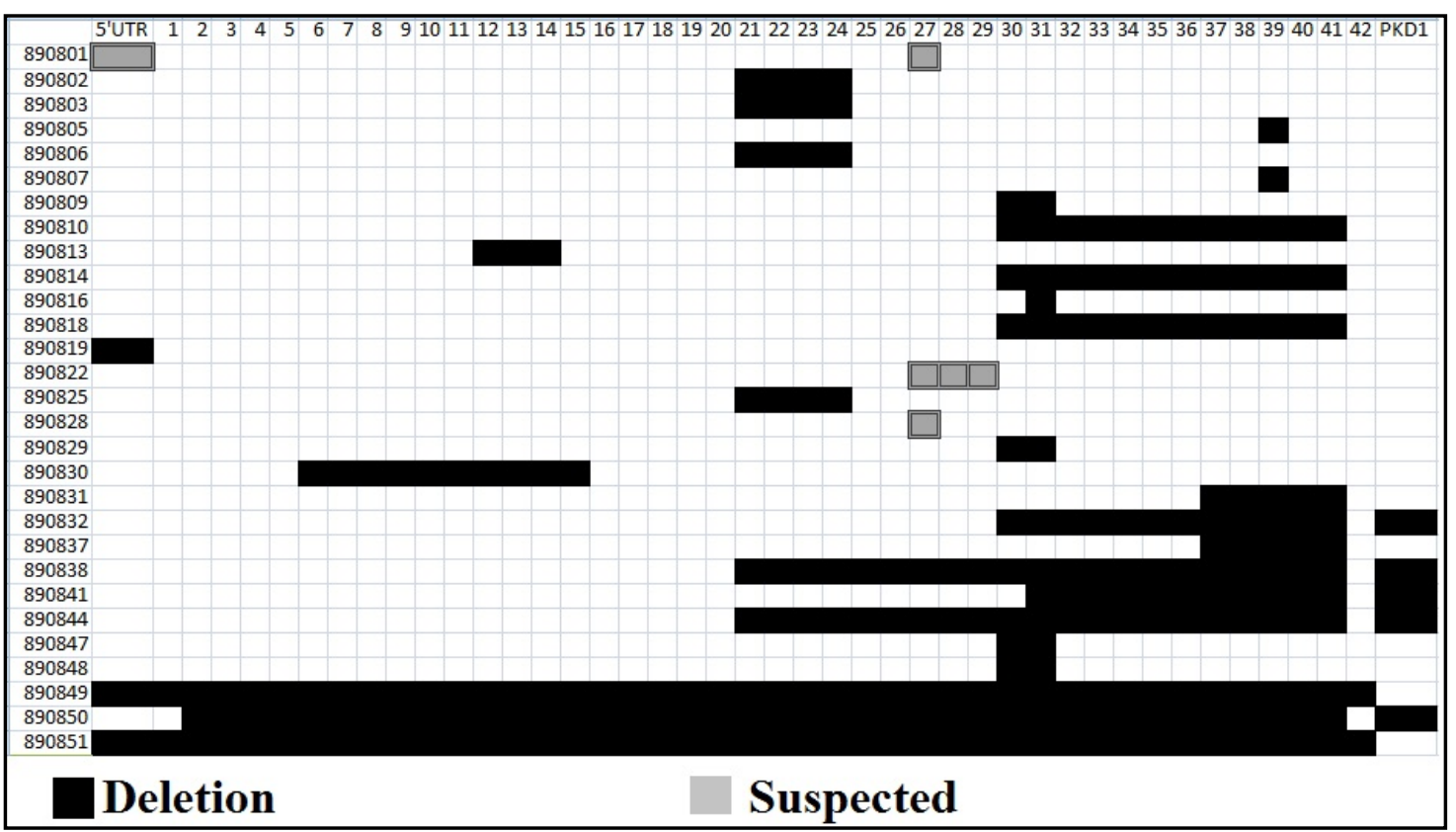

Figure 1. Deletion/duplication mutations in TSC2 gene. Deletions in each exon are shown in black and duplications are shown in gray. Numbers at the left are the specific code for each case and at the top numbers indicating numbers of exons. 
In the present study we found that duplications are much less common than deletions (only $10.3 \%$ with duplications). Our finding is consistent with the results that Kozlowski et al. revealed; they had a comprehensive study on large deletions/duplications of TSC1 and TSC2 in patients with TSC, which could find only two duplications in TSC2 [10].

From all patients of our study 8 were diagnosed with renal problems, but none of them had deletions in PKD1, and all PKD1 deletions were found in patients with no signs of kidney disorders, not considering one sample whose father had renal function impairment. According to previous studies, which have shown a strong relation between PKD1 deletions and kidney problems [10] [11], we should also consider the patients with deletion in PKD1 for kidney disorders in following studies (Figure 2).

Sporadic cases covering $70.37 \%$ of our study, which is in consistent with previous studies that estimated two thirds of tuberous sclerosis patients are sporadic [7].

Table 1. Distribution of TSC2 deletion/duplication in TSC patients.

\begin{tabular}{cccccccc}
\hline Group & \multicolumn{3}{c}{ Total } & \multicolumn{3}{c}{ Del } & \multicolumn{2}{c}{ Dup } \\
\hline Normal for TSC2 & $\mathrm{N}$ & $\%$ & $\mathrm{~N}$ & $\%$ & $\mathrm{~N}$ & $\%$ \\
Abnormal For TSC2 & 52 & 0.64 & 0 & 0.0 & 0 & 0.0 \\
Total & 29 & 0.36 & 26 & 32 & 3 & 4 \\
\hline
\end{tabular}

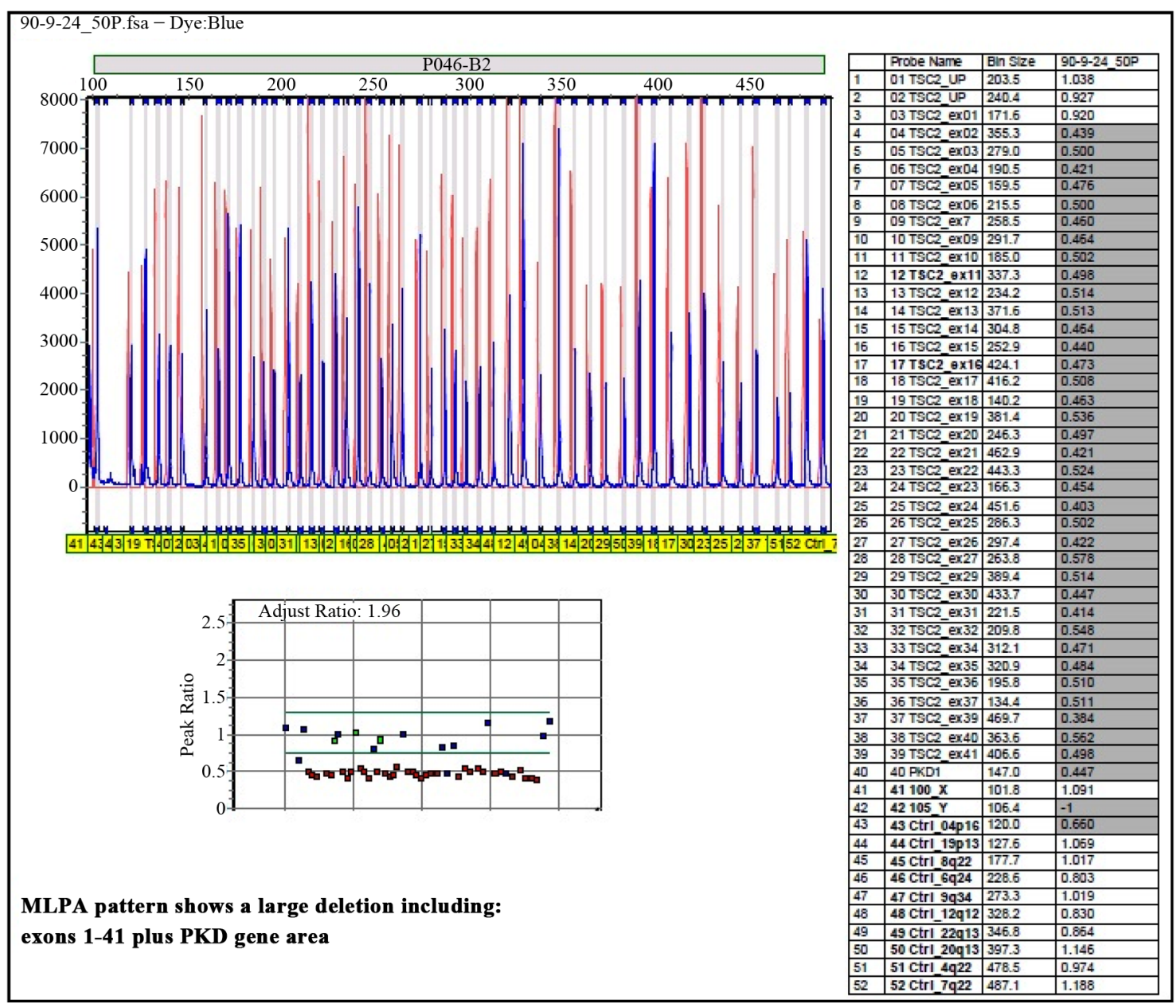

Figure 2. The report shows a large deletion covered entire gene including PKD1 gene. Comparisons of the red picks (Control probes) compared to the blue picks (Exon probes) show about 2-fold higher in the length which mean a large deletion. The results confirm a normalized adjusted pick ratio as well. 


\section{Acknowledgements}

This project was supported by grants from skin research center, Shahid Beheshti Medical Science University,

Tehran, Iran. We thank to Dr. Toosi, head of skin research center with our great pleasure for scientific help.

\section{References}

[1] Orlova, K.A. and Crino, P.B. (2010) The Tuberous Sclerosis Complex. Annals of the New York Academy of Sciences, 1184, 87-105. http://dx.doi.org/10.1111/j.1749-6632.2009.05117.x

[2] Sgro, M., Barozzino, T., Toi, A., et al. (1999) Prenatal Detection of Cerebral Lesions in a Fetus with Tuberous Sclerosis. Ultrasound in Obstetrics Gynecology, 14, 356-359. http://dx.doi.org/10.1046/j.1469-0705.1999.14050356.x

[3] Tonekaboni, S.H., Ebrahimi, A., Ahmadabadi, F., keyhanidoust, Z., Zamani, Gh., Rezvani, M., Amirsalari, S., Tavassoli, A. and Rounagh, A. (2012) Clinical and Para Clinical Manifestations of Tuberous Sclerosis: A Cross Sectional Study on 81 Pediatric Patients. Iranian Journal of Child Neurology, 6, 25-31.

[4] Hung, C.C., Su, Y.N., Chien, S.C., et al. (2006) Molecular and Clinical Analyses of 84 Patients with Tuberous Sclerosis Complex. BMC Medical Genetics, 7, 72. http://dx.doi.org/10.1186/1471-2350-7-72

[5] Ess, K.C. (2010) Tuberous Sclerosis Complex: A Brave New World? Current Opinion in Neurology, 23, 189-193. http://dx.doi.org/10.1097/WCO.0b013e32832c4ff5

[6] O’Callaghan, F.J. and Osborne, J.P. (2000) Advances in the Understanding of Tuberous Sclerosis. Archives of Disease in Childhood, 83, 140-142. http://dx.doi.org/10.1136/adc.83.2.140

[7] Jones, A.C., Shyamsundar, M.M., Thomas, M.W., et al. (1999) Comprehensive Mutation Analysis of TSC1 and TSC2-and Phenotypic Correlations in 150 Families with Tuberous Sclerosis. The American Journal of Human Genetics, 64, 1305-1315. http://dx.doi.org/10.1086/302381

[8] Jentarra, G.M., Rice, S.G., Olfers, S., et al. (2011) Evidence for Population Variation in TSC1 and TSC2 Gene Expression. BMC Medical Genetics, 12, 29. http://dx.doi.org/10.1186/1471-2350-12-29

[9] Nellist, M., Verhaaf, B., Goedbloed, M.A., et al. (2001) TSC2 Missense Mutations Inhibit Tuberin Phosphorylation and Prevent Formation of the Tuberin-Hamartin Complex. Human Molecular Genetics, 10, 2889-2898. http://dx.doi.org/10.1093/hmg/10.25.2889

[10] Kozlowski, P., Roberts, P., Dabora, S., et al. (2007) Identification of 54 Large Deletions/Duplications in TSC1 and TSC2 Using MLPA, and Genotype-Phenotype Correlations. Human Genetics, 121, 389-400. http://dx.doi.org/10.1007/s00439-006-0308-9

[11] Oyazato, Y., Iijima, K., Emi, M., et al. (2011) Molecular Analysis of TSC2/PKD1 Contiguous Gene Deletion Syndrome. Kobe Journal of Medical Sciences, 57, E1-E10.

[12] Wimmer, K., Yao, S., Claes, K., et al. (2006) Spectrum of Single- and Multiexon NF1 Copy Number Changes in a Cohort of 1100 Unselected NF1 Patients. Genes Chromosomes Cancer, 45, 265-276. http://dx.doi.org/10.1002/gcc.20289

[13] Schouten, J.P., McElgunn, C.J., Waaijer, R., et al. (2002) Relative Quantification of 40 Nucleic Acid Sequences by Multiplex Ligation-Dependent Probe Amplification. Nucleic Acids Research, 30, e57. http://dx.doi.org/10.1093/nar/gnf056

[14] Dabora, S.L., Jozwiak, S., Franz, D.N., et al. (2001) Mutational Analysis in a Cohort of 224 Tuberous Sclerosis Patients Indicates Increased Severity of TSC2, Compared with TSC1, Disease in Multiple Organs. The American Journal of Human Genetics, 68, 64-80. http://dx.doi.org/10.1086/316951 
Scientific Research Publishing (SCIRP) is one of the largest Open Access journal publishers. It is currently publishing more than 200 open access, online, peer-reviewed journals covering a wide range of academic disciplines. SCIRP serves the worldwide academic communities and contributes to the progress and application of science with its publication.

Other selected journals from SCIRP are listed as below. Submit your manuscript to us via either submit@scirp.org or Online Submission Portal.
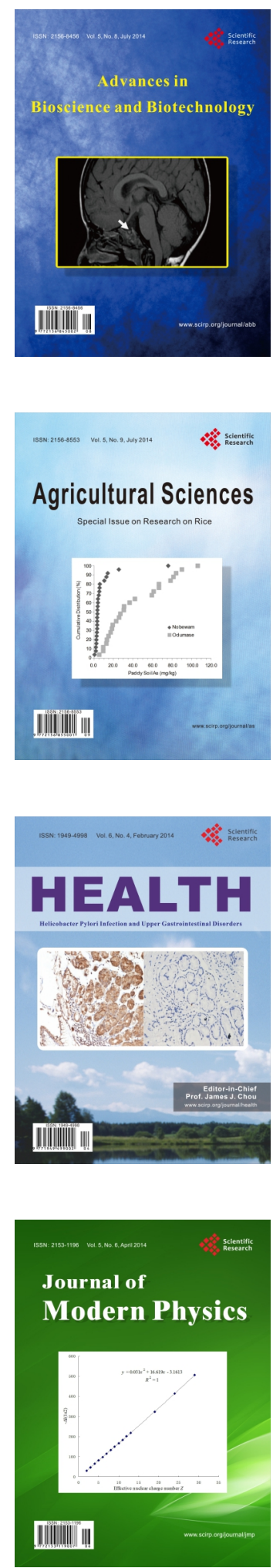
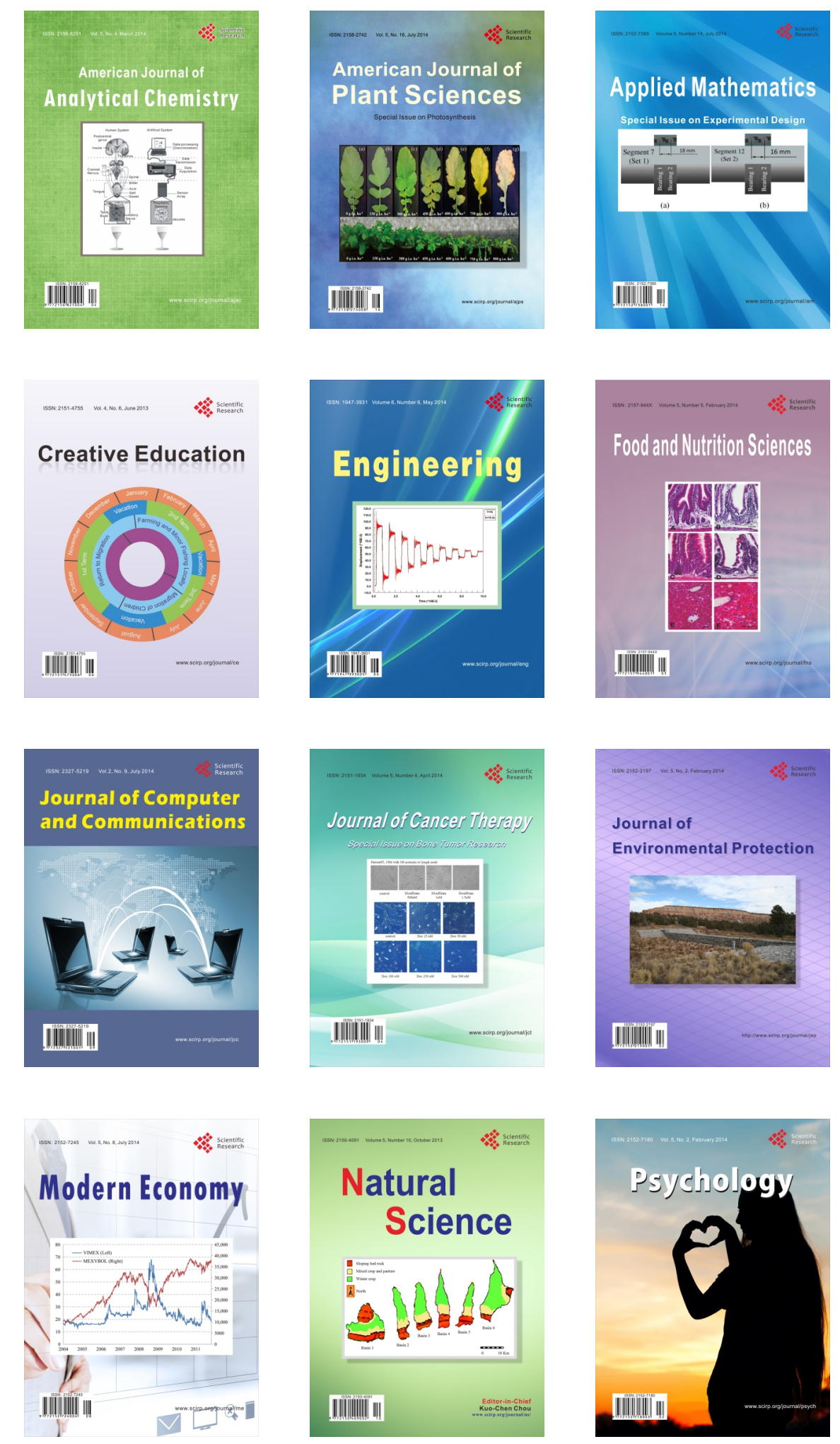